\title{
Crenças no paranormal e estilos de pensamento racional versus experiencial
}

\author{
Tatiana Severino de Vasconcelos ${ }^{1}$ \\ Bartholomeu Tôrres Tróccoli
}

\begin{abstract}
Resumo
Apesar dos avanços científicos e tecnológicos, as crenças em fenômenos paranormais têm aumentado nas últimas décadas. No entanto, não há um consenso sobre a estrutura multidimensional dessas crenças. Esse estudo procurou atingir dois objetivos: construir um questionário de crenças no paranormal (QCP) e observar sua dimensionalidade, além de investigar sua validade concorrente correlacionando seus resultados com o Inventário do Pensamento Racional versus Experiencial. Os instrumentos foram aplicados em 206 participantes e os resultados revelaram que o QCP divide-se em quatro fatores: crenças no paranormal em geral, superstições comuns, mal versus bem e proteção espiritual. As pessoas com maiores índices de crenças no paranormal e de superstições comuns tendem a preferir o pensamento experiencial. O pensamento racional não apresentou correlações significativas com nenhum dos fatores do QCP, sugerindo que não existem evidências empíricas para fundamentar a discussão das crenças no paranormal sobre a dicotomia racionalidade versus irracionalidade.

Palavras-Chave: Crenças no paranormal; Estilos de pensamento; Mensuração.
\end{abstract}

\section{Belief in the paranormal and rational versus experiential thinking styles}

\begin{abstract}
Despite of the scientific and technological advances, belief in the paranormality has been rising in the last decades. However, there is not an agreement about its multidimensional structure. This study intended to accomplish two goals: to construct a scale of paranormal beliefs (QCP) and observe its dimensionality, and investigate its concurrent validity by correlating its results with those of the Rational versus Experiential Thinking Inventory. The instruments were administered to 206 participants and the results revealed that QCP is composed of four factors paranormal beliefs, common superstitions, evil vs. good, and spiritual protection. People with higher beliefs in the paranormal and common superstitions tend to prefer experiential thinking. The rational thinking style did not correlate significantly with any of the QCP factors. These results suggest the non-existence of empirical evidence to support the rational versus irrational dichotomy as a way of understanding paranormal beliefs.

Keywords: Paranormal beliefs; Thinking styles; Measurement.
\end{abstract}

O fenômeno das crenças no paranormal é definido mais comumente de acordo com três critérios: a) é inexplicável em termos da ciência atual; b) a explicação é encontrada somente em amplas revisões dos limites básicos dos princípios da ciência; e c) há incompatibilidade com percepções normativas, crenças e expectativas da realidade (Otis \& Alcock, 1982; Tobacyk \& Milford, 1983; Tobacyk \& Wilkinson, 1991). Suas causas são complexas e a falta de educação formal é uma explicação inadequada, uma vez que pessoas com alto status socioeconômico, alto nível educacional e alto nível de inteligência também mantêm crenças aparentemente incompatíveis com essas características. Estudos realizados em diversos países (e.g., Grimmer e White, 1990; Jahoda, 1968; Otis \& Alcock, 1982; Tobacyk, Miller \& Jones, 1984; Zeidner \& Beit-Hallahmi, 1988) indicam que pessoas de diferentes culturas, diferentes níveis educacionais e diversos níveis de inteligência mantêm crenças sobrenaturais em maior ou menor grau.

Crenças supersticiosas comuns e crenças no paranormal são resultados altamente previsíveis de processos que controlam a aprendizagem e a cognição humana (Vyse, 1997). O comportamento supersticioso tende a surgir como uma resposta a eventos incontroláveis, levando o indivíduo a acreditar que mantém o controle da situação ou que pode prevê-la, reduzindo a ansiedade (Matute, 1995; Tobacyk \& Shrader, 1991), ou podem se constituir em um erro de interpretação de eventos normais considerados como eventos paranormais.

Em geral, as crenças aparecem associadas com características negativas de personalidade tais como dogmatismo (Rokeach, 1960; Tobacyk \& Milford, 1983); alienação e anomia (Tobacyk, 1985); dissociação e maior propensão a sugestionabilidade (Irwin, 1994); preferência

${ }^{1}$ Endereço para correspondência:

LabPAM, Instituto de Psicologia, UnB, ICC Sul - sala A1096 - Asa Norte - 70910-900 - Brasília-DF

Fone/Fax: (61) 307-1114

E-mail: tatianav@unb.br 
por jogos de azar (Tobacyk \& Wilkinson, 1991); menor auto-eficácia (Tobacyk \& Schrader, 1991); maior instabilidade emocional; depressão; ansiedade; baixa autoestima; dificuldade em enfrentar eventos estressores e até mesmo a esquizofrenia (Thalbourne, 1994).

Segundo Epstein (1994), o pensamento supersticioso faz parte do sistema experiencial das pessoas. Para ele, existem dois sistemas de processamento humano, o estilo de pensamento experiencial e o estilo de pensamento racional, que trabalham em paralelo, influenciando-se reciprocamente (Pacini \& Epstein, 1999). O sistema experiencial é um sistema pré-consciente, rápido, automático, holístico, associado ao afeto e às emoções. Em contraste, o sistema racional é um sistema consciente, analítico, mais lento e relativamente livre de emoção. O sistema racional opera com base nas regras de raciocínio transmitidas culturalmente. $O$ pensamento supersticioso faz parte do sistema experiencial das pessoas. No Brasil, uma pesquisa de Tróccoli e Santos (1997) encontrou evidências, em estudantes universitários, da relação entre crenças supersticiosas comuns e o estilo de pensamento experiencial. Tróccoli e Santos (1997) desenvolveram a Escala Brasileira de Superstições e Crenças (ECES) e verificaram correlações significativas entre as crenças em superstições comuns e estilos de pensamento mensurados pelo Inventário do Pensamento Racional versus Experiencial (RVEI-S) de Epstein, Norris e Pacini (1995). Os resultados mostraram que as pessoas com maiores índices de crença nas dimensões de superstições envolvendo sorte e azar também relatam maior habilidade e preferência pelo pensamento experiencial, enquanto as dimensões do pensamento racional não apresentaram nenhuma correlação significativa com as dimensões da ECES. Outros resultados mostraram que as mulheres foram significativamente mais crédulas quanto a superstições associadas à sorte e ao azar, estudantes de ciências exatas foram menos supersticiosos que os estudantes das ciências médicas/biológicas e das ciências humanas/sociais, e estudantes protestantes revelaram-se menos supersticiosos que os católicos, espíritas e sem religião. Outro estudo, realizado por Tróccoli, Vasconcelos, Meiçó, Rosa e Gomes (1999), também encontrou resultados semelhantes.

Pessoas mais crédulas também se percebem com menos sucesso e mais fracassos em vários contextos de suas vidas. Correlações entre uma medida de auto-eficácia (i.e., expectativa geral de sucesso ao realizar comportamentos que levam aos resultados esperados) e uma escala de mensuração de grau de crenças no paranormal revelaram uma associação inversa entre menor auto-eficácia e maior grau de crenças na dimensão das superstições comuns (Tobacyk \& Shrader, 1991).

Os processos cognitivos que levam as pessoas a adquirir e manter as crenças no paranormal são os mesmos que envolvem a habilidade para processar informações e tomar decisões, mas que também levam a erros de julgamento de probabilidade, o uso de heurísticos (regras e estratégias para simplificar o processamento de informações) e o uso de viéses de interpretação (Kahneman, Slovic \& Tversky, 1982; Nisbett \& Ross, 1980). Para ilustrar como uma crença pode surgir de um erro de julgamento de probabilidade, Blackmore e Troscianko (1985) descrevem o exemplo dos sonhos com eventos que acabam se realizando. Se uma pessoa sonha que bateu o carro e, no dia seguinte, realmente sofre um pequeno acidente de carro, pode concluir que o sonho foi algo paranormal. O evento é considerado tão improvável que alguma outra explicação além da coincidência é necessária. Ao explicar o sonho como uma premonição, entra também em ação o mecanismo de esquecimento seletivo. A pessoa pode se esquecer de todas as vezes que seus sonhos não se realizaram e relembrar apenas aquelas em que se concretizaram.

As crenças no paranormal são consideradas como respostas das pessoas a eventos incontroláveis (Matute, 1995) ou um sistema de crenças ao qual as pessoas recorrem quando se sentem desamparadas ao lidar com eventos de vida críticos (Epstein, conforme citado por Vyse, 1997). Indivíduos com maiores níveis de crenças paranormais possuem maior senso de controle de suas vidas (Williams \& Irwin, 1991) e percebem o mundo como algo mais previsível, difícil e justo, mas controlável (Tobacyk \& Milford, 1983). Indivíduos envolvidos com o paranormal também exibem evidências de se perceberem mais poderosos (Sheidt, 1973). Crenças dessa natureza podem fazer com que os problemas das pessoas pareçam menos difíceis e mais solucionáveis, diminuindo a probabilidade de ocorrências inesperadas e oferecendo esperanças de que os resultados possam ser influenciados. Isto também ocorre com relação às crenças religiosas, por exemplo. $\mathrm{O}$ envolvimento com uma religião (considerada como um tipo de crença no paranormal), pode aumentar a sensação de bemestar das pessoas e sua rede de suporte social (Myers, 2000). No campo da psicologia clínica, alguns autores afirmam que a inclusão da religião no tratamento psicoterápico pode ser bastante positiva quando as pessoas já são religiosas (Ellis, 2000).

Apesar das funções positivas de várias crenças supersticiosas, outras crenças também provocam conseqüências negativas tanto para o indivíduo quanto para a sociedade. Uma superstição ou crença paranormal pode se tornar um comportamento obsessivo, como evitar pisar nas rachaduras de calçadas; prejudicar um estudante quando acredita que, ao invés de estudar, basta dormir com o livro embaixo do travesseiro para obter uma nota satisfatória; ou causar a morte de pessoas que buscam cirurgias espirituais para se curar de doenças fatais.

\section{Medidas das crenças no paranormal e nas superstiçoes comuns}

As escalas utilizadas para mensurar o fenômeno 
das crenças paranormais refletem visões do fenômeno como sendo de natureza multivariada. No entanto, ainda não há um consenso sobre quantas e quais dimensões comporiam esta estrutura multidimensional. A Escala Brasileira de Crenças e Superstições (ECES) de Tróccoli e Santos (1997) possui três fatores de primeira ordem e um fator de segunda ordem, enquanto Tobacyk e Milford (1983) propuseram uma escala de crenças no paranormal com sete dimensões. Por outro lado, alguns estudos não chegam sequer a mencionar a dimensionalidade das escalas utilizadas. Os estudos analisados abrangem em geral as seguintes dimensões das crenças no paranormal (Grimmer \& White, 1990; Otis \& Alcock, 1982; Tobacyk \& Milford, 1983; Tróccoli \& Santos, 1997): crença em fenômenos paranormais (desenvolvimento de habilidades paranormais, existência de fenômenos estranhos); crença na pré-cognição (procura de videntes ou técnicas de previsão do futuro); crença em formas de vida alternativas (existência de extraterrestres, duendes, gnomos e bruxas); crença em terapias alternativas (uso de remédios ou tratamentos não-convencionais como cromoterapia, cura por cristais ou cirurgias espirituais); espiritualismo (comunicação com os mortos e reencarnação em outras vidas); crenças religiosas (envolve comportamentos como rezar para Deus, santos ou anjos, realizar promessas e acreditar na existência do demônio); feitiço e magia (prática de feitiços para se alcançar o que se deseja); e por último crença em superstições comuns (rituais comportamentais para atrair a sorte ou afastar o azar).

A inclusão da dimensão das crenças religiosas é um ponto controverso dentre as pesquisas sobre avaliação do paranormal. Os estudos que incluem essa dimensão justificam-se explicando que tanto as crenças paranormais quanto as crenças religiosas provavelmente originam-se da mesma experiência humana e possuem funções similares (Tobacyk \& Milford, 1983). Portanto, como as crenças religiosas estão presentes em outros instrumentos similares de mensuração de crenças, optou-se por incluí-las também neste estudo e observar o padrão de respostas dos sujeitos em tais itens.

Este estudo foi, então, desenvolvido para elaborar uma escala de mensuração das crenças no paranormal e das crenças comuns que possibilite uma descrição mais detalhada das suas dimensões. Paralelamente, procurou-se avaliar a validade concorrente da nova escala correlacionando-a com uma medida dos estilos de pensamento racional e experiencial. Espera-se que a nova escala apresente correlações significativas apenas com o estilo de pensamento experiencial.

\section{Método}

\section{Participantes}

A amostra consistiu de 206 indivíduos, sendo
91 homens e 107 mulheres (8 pessoas não informaram o sexo), entre estudantes universitários e funcionários públicos com média de idade de 29 anos (DP = 9,46). Quanto à escolaridade, 73,8\% possuía nível superior incompleto, enquanto 26,2 possuía nível superior completo. Dos 206 participantes, 21,8\% relataram algum tipo de envolvimento com o paranormal, ou seja, já leu algum livro sobre o assunto ou já participou de pelo menos um curso voltado para esta área.

\section{Instrumentos}

Questionário de Crenças no Paranormal- QCP. Para elaboração deste questionário foram traduzidos ou adaptados itens de instrumentos já existentes (Grimmer \& White, 1990; Tobacyk \& Milford, 1983; Tróccoli \& Santos, 1997) e elaborados novos itens baseados em artigos sobre crenças paranormais em revistas e jornais, resultando na seleção de 89 itens para compor o questionário. Esses itens foram submetidos à análise semântica por 2 grupos de 3 juízes. Estes sugeriram a reformulação de três itens para melhor compreensão dos respondentes e a inclusão de 11 novos itens referentes às crenças em superstições e crenças em extraterrestres. $\mathrm{O}$ conjunto final dos itens consistiu em 100 sentenças que expressam crenças comuns que devem ser avaliadas pelo respondente em uma escala tipo Likert de 7 pontos, sendo $1=$ discordo totalmente até $7=$ concordo totalmente, restando ainda a opção $0=$ não conheço/ nunca ouvi falar do assunto. Com base na literatura analisada, os itens do QCP foram elaborados para mensurar as seguintes dimensões: (1) crença em fenômenos paranormais; (2) crença em formas de vida alternativa; (3) crença em terapias alternativas; (4) espiritualismo; (5) crenças religiosas; (6) superstições comuns.

Inventário do Pensamento Racional versus Experiencial - RVEI-S. É a versão brasileira (Nunes, Tróccoli, Tamayo \& Pinheiro, 1999; Tróccoli, Laros, Moraes, Hostenski \& Araújo, 2000; Tróccoli, Nunes \& Rodrigues, 1999) do instrumento desenvolvido por Epstein (1995). Possui 40 itens, acompanhados de escalas tipo Likert, onde $1=$ completamente falsa e $5=$ completamente verdadeira, que procuram medir diferenças individuais quanto à predominância do pensamento experiencial versus racional. O sistema racional é um sistema inferencial que opera a partir da compreensão do indivíduo de regras de raciocínio transmitidas culturalmente, tendendo a ser consciente, analítico, mais lento e relativamente livre de emoção. Já o sistema experiencial consiste num sistema de aprendizagem pré-consciente, rápido, automático, holístico associado ao afeto e às emoções (Pacini \& Epstein, 1999). Tanto o inventário original quanto a sua versão brasileira apresentam quatro fatores de primeira ordem e oito fatores de segunda ordem, sendo eles: processamento racional, subdividido em habilidade racional e 
preferência racional; processamento experiencial, subdividido em habilidade experiencial e preferência pelo experiencial; depreciação dos modos de processamento, incluindo a depreciação do experiencial e depreciação do racional; e razãa sobre emoção, com as subdimensões assumindo a raz̃ão sobre a emoção e valorizando a razão acima da emoção. Estudos com o RVEI-S no Brasil indicam resultados semelhantes àqueles encontrados na amostra americana. Tróccoli e Santos (1997), em um estudo com 404 estudantes universitários, encontraram indicações de que as dimensões do racional e do experiencial são relativamente independentes entre si. Os índices de racionalidade apresentaram correlações significativas e positivas entre si e com os índices de valorização e preferência da razão sobre emoção. Também apresentaram correlações negativas com a depreciação do racional, enquanto nenhuma relação foi encontrada com o pensamento experiencial ou depreciação do experiencial. A dimensão do raciocínio experiencial apresentou correlações positivas e significativas com todos os índices da razão acima da emoção, correlação direta mas não significativa com a depreciação do racional e correlação negativa e significativa com a depreciação do experiencial. Nunes e colaboradores (1999) investigaram as correlações entre o RVEI-S e o Inventário do Pensamento Construtivo (Constructive Thinking Inventory - CTI-S) de Epstein e Meier (1989). A população testada apresentou média alta de pensamento experiencial, havendo diferenças significativas de acordo com as diferentes religiões. As dimensões de pensamento racional e pensamento experiencial apresentaram baixas correlações, indicando independência entre si.
Procedimento

Estudantes universitários e funcionários públicos foram abordados em sala de aula e nos ambientes de trabalho, ressaltando-se a participação voluntária e anônima. Os participantes receberam em conjunto o QCP e o RVEI-S, juntamente com questões demográficas como sexo, idade, escolaridade, religião, e questões sobre envolvimento e interesse no paranormal como: Você tem interesse ou está envolvido (a) com questões ligadas aos fenômenos paranormais e/ou alternativos?; Considerando possíveis treinamentos, cursos e leituras sobre fenômenos paranormais, qual das seguintes alternativas representa o seu caso? a) três ou mais livros e/ou cursos, b) um ou dois livros e cursos, c) nenhuma leitura ou treinamento.

\section{Resultados}

Uma análise dos componentes principais permitiu verificar, mediante exames do scree plot, dos valores dos eigenvalues e da matriz dos resíduos, a possível existência de 4 a 5 fatores. As primeiras análises fatoriais revelaram a adequação da solução com 4 fatores. Tal solução inicial revelou a existência de 8 itens que não apresentaram carga fatorial acima de 0,30 em nenhum fator. Esses itens foram descartados para novas análises utilizando-se o método de extração dos eixos principais e rotação varimax, resultando na adequação de uma solução com 4 fatores independentes, que explicam 46,07\% do total da variância da matriz original dos dados. A estrutura fatorial observada no QCP está reproduzida na Tabela 1. 
Tabela 1 - Cargas fatoriais e percentuais de variância dos itens do QCP obtidos com a extração dos fatores principais e rotação varimax

\begin{tabular}{|c|c|c|c|c|c|}
\hline Conteúdo dos itens & $\mathrm{F} 1^{\mathrm{a}}$ & Conteúdo dos itens & $\mathrm{F} 2$ & F 3 & F 4 \\
\hline Meditação & 0,78 & Varrer o pé e azar & 0,81 & - & - \\
\hline Desenv. do paranormal & 0,76 & Apontar estrelas e verruga & 0,76 & - & - \\
\hline Habilidades paranormais & 0,73 & Vestir roupa avesso azar & 0,74 & - & - \\
\hline Yoga e paranormal & 0,72 & Vassoura atrás da porta & 0,74 & - & - \\
\hline Auras & 0,71 & Levantar c/ pé direito & 0,71 & - & - \\
\hline Levitação & 0,69 & Cruzar os dedos e sorte & 0,71 & - & - \\
\hline Poderes paranormais & 0,69 & Orelha queimando & 0,72 & - & - \\
\hline Chakras & 0,67 & Jogar moedas em lagos & 0,70 & - & - \\
\hline Sonhos paranormais & 0,67 & Quebrar espelho azar & 0,68 & - & - \\
\hline Aura & 0,67 & Gatos pretos azar & 0,67 & - & - \\
\hline Transmissão de pensamento & 0,65 & Passar por cima pernas & 0,65 & - & - \\
\hline Levitação & 0,64 & Sapatos virados $\mathrm{p} /$ baixo & 0,64 & - & - \\
\hline Previsão do futuro & 0,62 & Passar debaixo escada & 0,64 & - & - \\
\hline Cromoterapia & 0,61 & Dólares na carteira & 0,63 & - & - \\
\hline Terapia de vidas passadas & 0,60 & Sereias & 0,60 & - & - \\
\hline Espírito deixa o corpo & 0,58 & Boto e lua cheia & 0,58 & - & - \\
\hline Reencarnação & 0,58 & Branco no ano novo & 0,53 & - & - \\
\hline Rapto por ET’s & 0,54 & Número treze & 0,48 & - & - \\
\hline Florais de Bach & 0,54 & Duendes do bem & 0,46 & - & - \\
\hline Cura psíquica & 0,51 & Atlântida localizada & 0,40 & - & - \\
\hline Iridologia & 0,50 & Alimentos grudados & 0,37 & - & - \\
\hline Magia & 0,49 & Provocar diabo & - & 0,79 & - \\
\hline Paranorm. e espíritos & 0,48 & Existe um demônio & - & 0,73 & - \\
\hline Paranormal e ciência & 0,45 & Maldade e sofrimento & - & 0,69 & - \\
\hline Deuses antigos & 0,45 & Demônio exorcizado & - & 0,60 & - \\
\hline Ocultismo & 0,42 & Céu e inferno & - & 0,57 & - \\
\hline Cirurgia espiritual & 0,41 & Deus existe & - & 0,49 & - \\
\hline \multirow[t]{7}{*}{ Existência de bruxas } & 0,41 & Vodu & - & 0,43 & - \\
\hline & & Crença em Deus & - & 0,32 & - \\
\hline & & Santos milagrosos & - & - & 0,76 \\
\hline & & Devoção aos santos & - & - & 0,62 \\
\hline & & Anjos da guarda & - & - & 0,57 \\
\hline & & Cumprir promessas & - & - & 0,49 \\
\hline & & Sorte & - & - & 0,41 \\
\hline Percentual de variância explicada & 17,5 & Percentual de variância explicada & 15,2 & 5,3 & 4,5 \\
\hline Número de itens & 28 & Número de itens & 21 & 8 & 5 \\
\hline
\end{tabular}

a Nomes dos fatores: F1: crenças no paranormal em geral; F2: Superstições comuns; F3: crenças no mal versus bem; F4: proteção espiritual

O fator $1 \mathrm{da}$ Tabela 1 representa as crenças no paranormal em geral $($ alfa $=0,94)$, abrangendo itens sobre crenças esotéricas como transmissão de pensamento, previsão de futuro, meditação, levitação, bruxas e magia, estudo dos chakras e reencarnação, sobre desenvolvimento das habilidades paranormais e sobre terapias alternativas como cromoterapia e iridologia. $\mathrm{O}$ fator 2, denominado superstições comuns (alfa $=0,93$ ), compreende as crenças em diferentes superstições populares destinadas a atrair resultados favoráveis ou 
realizar desejos e superstições que envolvem atos que possam trazer conseqüências negativas mais sérias como deformidades físicas ou azar. $\mathrm{O}$ fator 3 representa crenças em forças malignas e benignas e é denominado mal versus bem (alfa $=0,81)$. Esse fator representa a dicotomia entre as forças do mal e do bem, sendo que a primeira constitui-se na existência do demônio e de práticas que podem prejudicar as pessoas, enquanto a segunda constitui-se na existência de Deus e de seus benefícios para os indivíduos. $\mathrm{O}$ fator 4 , proteção espiritual (alfa = 0,78 ), envolve aquelas crenças que aparentam servir de mecanismos de coping diante dos estresses e incertezas da vida, constituindo-se em práticas religiosas (especialmente da igreja católica), que protegem as pessoas.

A Tabela 2 apresenta as correlações com parcialização de gênero entre RVEI-S e QCP; isso significa que a influência da variável gênero nas correlações é controlada, eliminando-se, estatisticamente, qualquer variância devida ao gênero. Os resultados revelam relações positivas e significativas entre a dimensão do QCP crenças no paranormal com as dimensões do RVEI-S processamento experiencial, habilidade experiencial e preferência pelo experiencial, indicando que as pessoas que relataram maiores crenças em práticas paranormais, tais como levitação, estudo de chakras e previsão do futuro, são aquelas que relatam maior uso e maior habilidade e preferência pelo modo experiencial de processamento de informações. Também foram observadas correlações significativas entre o processamento experiencial e a proteção espiritual, indicando que pessoas mais religiosas, que acreditam em anjos e santos, também apresentam uma tendência a processar informações de modo mais intuitivo. A dimensão de crenças em supersticões comuns correlacionou-se positivamente com a habilidade experiencial, ou seja, aqueles que julgam possuir habilidades intuitivas acreditam mais nas superstições para atrair sorte ou afastar o azar. A dimensão mal versus bem não se correlacionou com nenhuma das dimensões do RVEI-S. Correlações negativas e significativas foram encontradas apenas entre as crenças no paranormal e as dimensões de depreciação de estilos de pensamento e depreciação do experiencial do RVEI-S, demonstrando que uma maior crença no paranormal pode indicar uma menor depreciação dos modos de pensamento, e em particular do pensamento experiencial. O processamento racional e suas subdimensões não apresentaram correlações significativas com nenhuma das dimensões do QCP.

Tabela 2 - Correlações entre dimensões e subdimensões do QCP e do RVEI-S com parcialização de gênero (N=191)

\begin{tabular}{lcccc}
\hline DIMENSÕES & $\begin{array}{c}\text { Crenças no } \\
\text { Paranormal }\end{array}$ & $\begin{array}{c}\text { Superstições } \\
\text { Comuns }\end{array}$ & Mal vs Bem & $\begin{array}{c}\text { Proteção } \\
\text { Espiritual }\end{array}$ \\
\hline 1. Processamento racional & 0,01 & $-0,12$ & $-0,10$ & $-0,06$ \\
1.1. Habilidade racional & 0,02 & $-0,09$ & 0,00 & 0,04 \\
1.2. Preferência pelo racional & 0,01 & $-0,10$ & $-0,13$ & $-0,10$ \\
2. Processamento experiencial & $0,31^{* *}$ & 0,14 & 0,10 & $0,21^{*}$ \\
2.1. Habilidade experiencial & $0,27^{* *}$ & $0,21^{*}$ & 0,18 & 0,19 \\
2.2. Preferência experiencial & $0,25^{* *}$ & 0,05 & 0,02 & 0,16 \\
3. Depreciação & $-0,24^{* *}$ & 0,02 & 0,08 & $-0,03$ \\
3.1. Depreciação do experiencial & $-0,29^{* *}$ & $-0,05$ & 0,03 & $-0,10$ \\
3.2. Depreciação do racional & $-0,07$ & 0,10 & 0,11 & 0,07 \\
4. Razão sobre emoção & $-0,09$ & 0,08 & 0,07 & $-0,04$ \\
5. Assumir razão sobre emoção & $-0,07$ & 0,03 & 0,01 & $-0,06$ \\
6. Valorizar razão sobre emoção & $-0,08$ & 0,09 & 0,09 & $-0,00$ \\
\hline
\end{tabular}

Nota: ${ }^{* *}$ Correlações são significativas a $p \leq 0,01$

${ }^{*}$ Correlações são significativas a $p \leq 0,05$

A postura de assumir a razão sobre a emoção, representada pelas dimensões razão acima da emoção, assumindo a raz̃ão sobre a emoção e valorizando a razão acima da emoção do RVEI-S apresentaram correlações próximas de zero ou negativas, porém não significativas, com todas as dimensões do QCP; ou seja, valorizar a razão ou assumir essa postura parece independer das crenças no paranormal, em superstições ou na existência de forças do mal ou do bem.

A Tabela 3 lista as médias nas dimensões do QCP de acordo com ausência ou não de treinamento e envolvimento com o paranormal e as preferências religiosas dos participantes. Conforme estes resultados, as pessoas que relataram algum envolvimento nas práticas paranormais mostram-se significativamente mais crédulas somente na dimensão crenças no paranormal. A menor média para o grupo de pessoas que relatou algum envolvimento com $\mathrm{o}$ paranormal refere-se às crenças em superstições comuns. Já a quantidade de treinamento no paranormal dos participantes, ou seja, leitura de livros relacionados 
ao assunto ou participação em cursos, apresentou relações significativas apenas em uma dimensão do QCP. As pessoas que relataram ter passado por algum tipo de treinamento demonstraram acreditar mais nos tratamentos alternativos, desenvolvimentos das habilidades paranormais e práticas paranormais em geral, representadas pelas crenças no paranormal em geral.

As médias da Tabela 3 também mostram que protestantes se diferenciam significativamente dos demais grupos, relatando menor índice de crenças no paranormal, superstiçôes comuns e proteção espiritual, tais como crenças em anjos e santos protetores. Por outro lado, os protestantes apresentaram crenças significativamente maiores na dimensão mal versus bem, que representa a dicotomia entre as forças do mal e a existência de Deus. Já os espíritas demonstram os maiores índices de credulidade na dimensão crenças no paranormal, que abrange também itens pertencentes a essa religião como existência de vidas passadas e reencarnação. Os católicos, conforme esperado, apresentaram médias significativamente mais altas na dimensão proteção espiritual. Essa dimensão possui itens como devoção aos santos protetores, cumprimento de promessas e existência de anjos, elementos bastante evidenciados na religião católica. Os participantes sem religião relataram menor índice de credulidade apenas na dimensão mal versus bem, porém, do ponto de vista estatístico, diferem apenas dos protestantes. Finalmente, embora as médias das mulheres tenham sido ligeiramente maiores que a dos homens em todas as dimensões do QCP, as diferenças não foram estatisticamente significativas.

Tabela 3 - Médias e desvios padrões nos fatores do QCP de acordo com a religião dos participantes, treinamento e envolvimento com o paranormal $(\mathrm{N}=197)$

\begin{tabular}{|c|c|c|c|c|}
\hline QCP & $\begin{array}{l}\text { Crenças no } \\
\text { Paranormal }\end{array}$ & $\begin{array}{l}\text { Superstições } \\
\text { Comuns }\end{array}$ & Mal vs. Bem & $\begin{array}{l}\text { Proteção } \\
\text { Espiritual }\end{array}$ \\
\hline \multicolumn{5}{|l|}{ Religião } \\
\hline $\begin{array}{l}\text { Católica }(n=132) \\
\text { Protestante }(n=23) \\
\text { Espírita }(n=21) \\
\text { Sem religião }(n=30)\end{array}$ & $\begin{array}{l}4,24(0,83) \\
2,96(1,02) \\
5,15(1,32) \\
4,60(1,10)\end{array}$ & $\begin{array}{l}2,52(1,02) \\
1,94(0,81) \\
2,32(0,76) \\
2,26(0,90)\end{array}$ & $\begin{array}{l}4,37(1,12) \\
5,45(0,75) \\
4,06(1,08) \\
3,77(1,24)\end{array}$ & $\begin{array}{l}4,85(1,13) \\
3,12(0,98) \\
4,54(1,33) \\
4,10(1,11) \\
\end{array}$ \\
\hline \multicolumn{5}{|l|}{$\begin{array}{l}\text { Treinamento em práticas } \\
\text { paranormais }\end{array}$} \\
\hline $\begin{array}{l}\text { Com treinamento }(n=71) \\
\text { Sem treinamento }(n=117)\end{array}$ & $\begin{array}{l}4,72(1,12) \\
4,00(0,97)\end{array}$ & $\begin{array}{l}2,44(0,86) \\
2,44(1,04)\end{array}$ & $\begin{array}{l}4,30(1,09) \\
4,32(1,17)\end{array}$ & $\begin{array}{l}4,68(1,06) \\
4,48(1,30)\end{array}$ \\
\hline \multicolumn{5}{|l|}{$\begin{array}{l}\text { Envolvimento com práticas } \\
\text { paranormais }\end{array}$} \\
\hline $\begin{array}{l}\text { Sem envolvimento }(n=153) \\
\text { Com envolvimento }(n=45)\end{array}$ & $\begin{array}{l}3,95(1,00) \\
5,19(0,77)\end{array}$ & $\begin{array}{l}2,41(1,02) \\
2,35(0,81)\end{array}$ & $\begin{array}{l}4,38(1,19) \\
4,17(1,10)\end{array}$ & $\begin{array}{l}4,46(1,27) \\
4,72(1,07)\end{array}$ \\
\hline
\end{tabular}

\section{Discussão e conclusão}

Os resultados da análise fatorial do QCP apontam para a existência de uma dimensionalidade menos complexa que aquela relatada nos estudos de Tobacyk e Milford (1983) e Grimmer e White (1990), ambos com sete dimensões e nenhuma subdimensão. A estrutura multidimensional do QCP, com quatro dimensões, constituindo um grande fator de crenças no paranormal e mais três fatores relacionados a superstições, crenças no mal versus bem e proteção espiritual, sugere que as crenças no paranormal compõem um fenômeno complexo com diversos aspectos. Além disso, é clara a distinção entre as crenças no paranormal que abrangem magia, curas alternativas, crença em seres fantásticos, práticas como levitação e previsão do futuro e as crenças em superstições, rituais cotidianos para atrair a sorte e afastar o azar. Os dois fatores restantes remetem a aspectos religiosos, como a Psico-USF, v. 9, n. 2, p. 155-164, Jul./Dez. 2004 existência de Deus e do diabo e a proteção de anjos e santos. Portanto, os quatro fatores possuem itens que correspondem à definição de crenças no paranormal como algo inexplicável em termos da ciência atual, contudo se diferenciam claramente quanto ao conteúdo que abrangem. As duas últimas dimensões mal versus bem e proteção espiritual também têm sido estudadas no contexto da Psicologia da Religião (Emmons \& McCullough, 1999; Emmons \& Paloutzian, 2003; Parke, 2001; Sinnott, 2001).

Pessoas mais supersticiosas e com maior crença no paranormal tendem a relatar uma maior habilidade e preferência pelo pensamento experiencial, confirmando os estudos de Epstein (1994), Tróccoli e Santos (1997), Tróccoli e colaboradores (1999) e Vasconcelos (2001) Para Seymour Epstein, as superstições são provenientes do sistema intuitivo experiencial. Este sistema é mais antigo e mais adaptativo que o sistema racional analítico, pois possibilita que as pessoas processem rapidamente e 
de forma automática uma grande quantidade de informações através, por exemplo, do uso de heurísticos e atalhos cognitivos (Kahneman, Slovic \& Tversky, 1983). Dessa forma, as superstições devem ser compreendidas como manifestações com funções adaptativas, exatamente como erros e vieses de julgamento são efeitos colaterais adaptativos provocados por algumas situações limite.

O fator do QCP proteção espiritual também apresenta um caráter adaptativo: os que procuram a proteção de anjos e santos e fazem promessas apresentaram maiores índices na dimensão pensamento experiencial. É possível que, para tais indivíduos, a crença em entidades que as protegem e auxiliam nos seus problemas ocasionem uma maior sensação de controle e conforto, resultando portanto em estratégias adaptativas e de enfrentamento. Observa-se que o fator proteção espiritual, conforme mensurado pelo QCP, abrange apenas alguns aspectos presentes nas crenças religiosas. Outros estudos pesquisaram o papel mais abrangente das crenças religiosas em geral, incluindo a crença em anjos e santos e o hábito de freqüentar templos e igrejas, encontrando resultados positivos. Práticas e crenças religiosas têm sido associadas a uma maior sensação de bem-estar (Myers, 2000; Mahoney e colaboradores, 1999), menores índices de depressão (Maton, 1989) e têm sido indicadas como formas positivas de coping (Ellison, 1991). Pesquisas em hospitais, por exemplo, indicaram que pacientes religiosos infectados com o vírus HIV apresentaram menor sensação de desespero e desamparo do que pacientes não-religiosos (Carson, Soeken, Shanty \& Terry, 1990). Para Murphy e colaboradores (2000) isso ocorre porque a religião, qualquer que seja ela, pode proporcionar aos indivíduos recursos cognitivos para encontrar significado em um evento negativo, levando a formas positivas de enfrentamento (ver, no entanto, posição diversa em Boyer, 2001).

Apesar dos efeitos positivos das crenças em geral, em relação à sensação de controlabilidade dos eventos ou maior sensação de bem-estar, é necessário observar também os efeitos negativos de crenças em excesso e o uso predominante do sistema de processamento experiencial (Epstein, Pacini, Denes-Raj \& Heier, 1996). O processamento experiencial leva ao ajustamento quando auxilia o indivíduo no processamento rápido de uma grande quantidade de informações, na associação de idéias e na generalização. Porém, o desajustamento ocorre quando as informações são processadas de forma pouco crítica ou excessivamente emocional. A perda de tempo com rituais e superstições, guerras e genocídios por razões religiosas, extermínio de animais para obtenção de poderes especiais e a vitimização por charlatães, são exemplos comuns dos malefícios das crenças supersticiosas.

$\mathrm{O}$ fato de as respostas das pessoas que se julgam mais racionais não apresentarem relações com as diversas dimensões do QCP indica que não existem evidências empíricas para fundamentar a discussão das crenças paranormais sobre a dicotomia Racionalidade versus Irracionalidade. De fato, Jahoda (1968) considera pejorativa e preconceituosa a relação entre crenças em superstições e funcionamento cognitivo menos efetivo. Neste trabalho considera-se que as crenças paranormais servem importantes funções motivacionais, ajudando o indivíduo a compreender a si mesmo e o mundo em sua volta, além de prover uma sensação de controle sobre os eventos cotidianos (cf. Lillqvist \& Lindeman, 1998).

Algumas outras características dos indivíduos também devem ser observadas. Seguindo o observado por Zeidner e Beit-Hallahmi (1988), as mulheres apresentaram uma tendência, embora não significativa estatisticamente, de maior credulidade que os homens. A religião dos participantes exerceu igualmente uma influência considerável no grau de crenças dos participantes. Os protestantes foram os menos crédulos em quase todas as dimensões, corroborando resultados anteriores apresentados por Tróccoli e Santos (1997). O grupo dos católicos se diferenciou significativamente dos demais na dimensão de proteção espiritual relativa a proteção de santos, promessas e anjos. Finalmente, os espíritas descreveram-se mais crédulos nas crenças no paranormal, onde predominam itens sobre reencarnação e existência de vidas passadas.

O grau de envolvimento com o paranormal é outra característica que também diferencia os indivíduos: aqueles sem nenhum envolvimento, e sem treinamento ou cursos nas áreas místicas, são significativamente mais céticos nas crenças no paranormal. McGarry e NewBerry (1981) também verificaram que pessoas com maior envolvimento com o paranormal apresentam índices mais elevados de crenças supersticiosas.

Além desses resultados, o Questionário de Crenças no Paranormal (QCP) também apresentou índices promissores de validade. Sua consistência interna (índices alfa adequados para os fatores) e as correlações com o RVEI-S corroboraram achados anteriores apontando para a validade de construto e convergente do QCP.

Embora os objetivos básicos deste trabalho tenham sido atingidos, duas limitações devem ser ressaltadas no que diz respeito ao estudo da natureza das crenças no paranormal. Primeiro, a amostra, formada predominantemente por estudantes universitários, apresenta um nível baixo de crenças quando comparada com a população em geral, além de não precisar utilizar as estratégias adaptativas da maioria da população brasileira, que trabalha em tempo integral ou é desempregada. Segundo, características de personalidade tais como locus de controle (Scheidt, 1973), necessidade por estrutura (Neuberg, \& Newsom, 1993), auto-eficácia (Tobacyk \& Schrader, 1991) ou estilos de coping (Epstein \& Meier, 1989; Tróccoli, 2004) podem mediar ou moderar várias 
outras dimensões relevantes, além dos estilos de pensamento, que podem estar ligadas às crenças supersticiosas. Investigações de modelos mais complexos, via equações estruturais, por exemplo, serão necessárias para continuar explorando o fenômeno das crenças no paranormal.

\section{Referências}

Boyer, P. (2001). Religion explained. The evolutionary origins of religious thought. New York: Basic Books.

Carson, V., Soeken, K. L., Shanty, J. \& Terry, L. (1990). Hope and spiritual well-being: Essentials for living with AIDS. Perspectives in Psychiatric Care, 26, 28-34.

Ellis, A. (2000). Can Rational Emotive Behavior Therapy (REBT) be effectively user with people who have devout beliefs in God and religion. Professional Psychology: Research and Practice, 31, 29-33.

Ellison, C. W. (1991). Race, religious involvement and depressive symptomatology in a southeastern U. S. community. Social Science and Medicine, 40, 1561-1572.

Emmons, R. A. \& Paloutzian, R. F. (2003). The psychology of religion. Annual Review of Psychology, 54, 377-402.

Emmons, R. A. \& McCullough, M. E. (1999). Religion in the psychology of personality. Journal of Personality, 67, 874-1218.

Epstein, S. (1994). Integration of the cognitive and the psychodynamic unconscious. American Psychologist, 49, 709-724.

Epstein, S. \& Meier, P. (1989). Constructive thinking: A broad coping variable with specific components. Journal of Personality and Social Psychology, 57, 332-350.

Epstein, S., Norris, R. \& Pacini, R. (1995). The Rational versus Experiential Inventory-Short Form. Manuscrito não publicado.

Epstein, S., Pacini, R., Denes-Raj, V. \& Heier, H. (1996). Individual differences in intuitive - Experiential and analytical - Rational thinking styles. Journal of Personality and Social Psychology, 71(2), 390-405.

Grimmer, M. R. \& White, K. D. (1990). The structure of paranormal beliefs among Australian psychology students. The Journal of Psychology, 124, 354-370.

Irwin, H. J. (1994). Paranormal belief and proneness to dissociation. Psychological Reports, 75, 1344-1346.

Jahoda, G. (1968). Scientific training and the persistence of traditional beliefs among West African University students. Nature, 220, 1356.

Kahneman, D., Slovic, P. \& Tversky, A. (1982). Judgment under uncertainty: Heuristics and biases. Cambridge: Cambridge University Press.
Lillqvist, O. \& Lindeman, M. (1998). Belief in astrology as a strategy for self-verification and coping with negative life-events. European Psychologist, 3, 202-208.

Mahoney, A., Pargament, K. I., Jewell, T., Swank, A. B., Scott, E., Emery, E. \& Rya, M. (1999). Marriage and the spiritual realm: The role of proximal and distal religious constructs in marital functioning. Journal of Family Psychology, 13, 321-338.

Maton, K. I. (1989). The stress-buffering role of spiritual support: Cross-sectional and prospective investigations. Journal for the Scientific Study of Religion, 28, 310-323.

Matute, H. (1995). Human reactions to uncontrollable outcomes: Further evidence for superstitions rather than helplessness. The Quarterly Journal of Experimental Psychology, 48, 142-157.

McGarry, J. J. \& Newberry, B. H. (1981). Beliefs in paranormal phenomena end locus of control: A filed study. Journal of Personality and Social Psychology, 41, 725-736.

Murphy, P. E., Ciarrocchi, J. W., Piedmont, R. L., Cheston, S., Peyrot, M. \& Fitchett, G. (2000). The relation of religious belief and practices, depression, and hopelessness in persons with clinical depression. Journal of Consulting and Clinical Psychology, 68, 1102-1106.

Myers, D. G. (2000). The funds, friends, and faith of happy people. American Psychologist, 55, 56-67.

Neuberg, S. L. \& Newsom, J. T. (1993). Personal need for structure: Individual differences in the desire for simple structure. Journal of Personality and Social Psychology, 65, 113-131.

Nisbett, R. \& Ross, L. (1980). Human Inference: Strategies and shortcomings of social judgement. Englewood Cliffs, NJ: Prentice-Hall.

Nunes, C. M. P., Tróccoli, B. T., Tamayo, M. R. \& Pinheiro, F. A. (1999). Racionalidade e coping: correlações entre o Inventário do Pensamento Construtivo (CTI) e a forma abreviada do Inventário do Pensamento Racional vs. Experiencial (RVEI-S). Em Sociedade Brasileira de Psicologia (Org.). Resumos de comunicações cientificas, XXIX Reunião Anual de Psicologia. Campinas, SP: SBP.

Otis, L. \& Alcock, J. (1982). Factors affecting extraordinary belief. The Journal of Social Psychology, 118, 77-85.

Pacini, R. \& Epstein, S. (1999). The relation of rational and experiential information processing styles to personality, basic beliefs, and the ratio-bias phenomenon. Journal of Personality and Social Psychology, 76, 972-987.

Parke, R. D. (2001). Introduction to the special section on families and religion: A call for a recommitment 
by researchers, practitioners, and policymakers. Journal of Family Psychology, 15, 555-558.

Rokeach, M. (1960). The open and the closed mind. New York: Basic Books.

Scheidt, R. J. (1973). Beliefs in supernatural phenomena and locus of control. Psychological Reports, 32, 1959-1962.

Sinnott, J. D. (2001). Relations between spirit and adult development in healing techniques in several cultures. Journal of Adult Development, 8(4), 241-247.

Thalbourne, M. A. (1994). Belief in the paranormal and its relationship to schizophrenia-relevant measures: A confirmatory study. British Journal of Clinical Psychology, 33, 78-80.

Tobacyk, J. (1985). Paranormal beliefs, alienation and anomie in college students. Psychological Reports, 57, 844-846.

Tobacyk, J. \& Milford, G. (1983). Belief in paranormal phenomena: Assesment instrument development and implications for personality functioning. Journal of Personality and Social Psychology, 44, 1029-1037.

Tobacyk, J., Miller, M. J. \& Jones, G. (1984). Paranormal beliefs of high school students. Psychological Reports, $55,255-261$.

Tobacyk, J. \& Shrader, D. (1991). Superstition and selfefficacy. Psychological Reports, 68, 1387-1388.

Tobacyk, J. J. \& Wilkinson, L. V. (1991). Paranormal beliefs and preferences for games of chance. Psychological Reports, 68, 1088-1090.

Tróccoli, B. T. (2004). Teoria do self cognitivo experiencial. Em M. F. Dela Coleta (Org.). Modelos para pesquisa e modificação de comportamentos de saúde (pp. 89129). Taubaté, SP: Cabral Editora e Livraria Universitária.

Tróccoli, B. T., Nunes, C. M. P. \& Rodrigues, M. M. M. (1999). Pensamento experiencial \& racional: mensurações e implicações (Resumo). Em Sociedade
Brasileira para o Progresso da Ciência (Org.). Resumos de comunicacõoes científicas, 51a. Reunião Anual da Sociedade Brasileira para o Progresso da Ciência-SBPC. Porto Alegre, Rio Grande do Sul.

Tróccoli, B. T., Laros, J. A., Moraes, P. B., Hostensky, E. L. \& Araújo, R. M. (2000). Relações entre Pensamento Racional vs. Experiencial e os Cinco Fatores de Personalidade (Resumo). Em Associação Brasileira de Psicologia Social (Org.). Resumos de comunicaçôs científicas, 52a. Reunião Anual da SBPC. Brasília, DF.

Tróccoli, B. T. \& Santos, S. (1997). A estrutura fatorial das superstições e suas relaçôes com tipos de raciocínio. Manuscrito não-publicado. Universidade de Brasília.

Tróccoli, B. T., Vasconcelos, T. S., Meiço, C. A., Rosa, A. B. R. \& Gomes, C. M. (1999). Desenvolvimento do questionário de crenças no paranormal (QCP) dados preliminares (Resumo). Em Sociedade Brasileira de Psicologia (Org.). Resumos de comunicações científicas, XXIX Reunião Anual de Psicologia. Campinas, SP.

Vasconcelos, T. S. (2001). Desenvolvimento do Questionário de Crenças no Paranormal (QCP): dados preliminares (Dissertação de Mestrado). Distrito Federal: Universidade de Brasília - Instituto de Psicologia.

Vyse, S. A. (1997). Believing in magic. Oxford, New York: Oxford University Press.

Williams, L. M. \& Irwin, H. J. (1991). A study of paranormail belief, magical ideation as an index of schozotypy and cognitive style. Personality and Individual Differences, 12, 1339-1348.

Zeidner, M. \& Beit-Hallagmi, B. (1988). Sex, ethnic and social class differences in parareligious beliefs among Israeli adolescents. The Journal of Social Psychology, 128, 333-343.

Recebido em maio de 2004 Reformulado em outubro de 2004 Aprovado em dezembro de 2004

Sobre os autores:

Tatiana Severino de Vasconcelos é mestre em Psicologia Social e do Trabalho e doutoranda em Psicologia pela Universidade de Brasília, vinculada ao Laboratório de Pesquisa em Avaliação e Medida.

Bartholomeu Tôrres Tróccoli é doutor pela Universidade de Madison, Wisconsin, professor do Departamento de Psicologia Social e do Trabalho e desenvolve suas pesquisas no Laboratório de Pesquisa em Avaliação e Medida na Universidade de Brasília. 